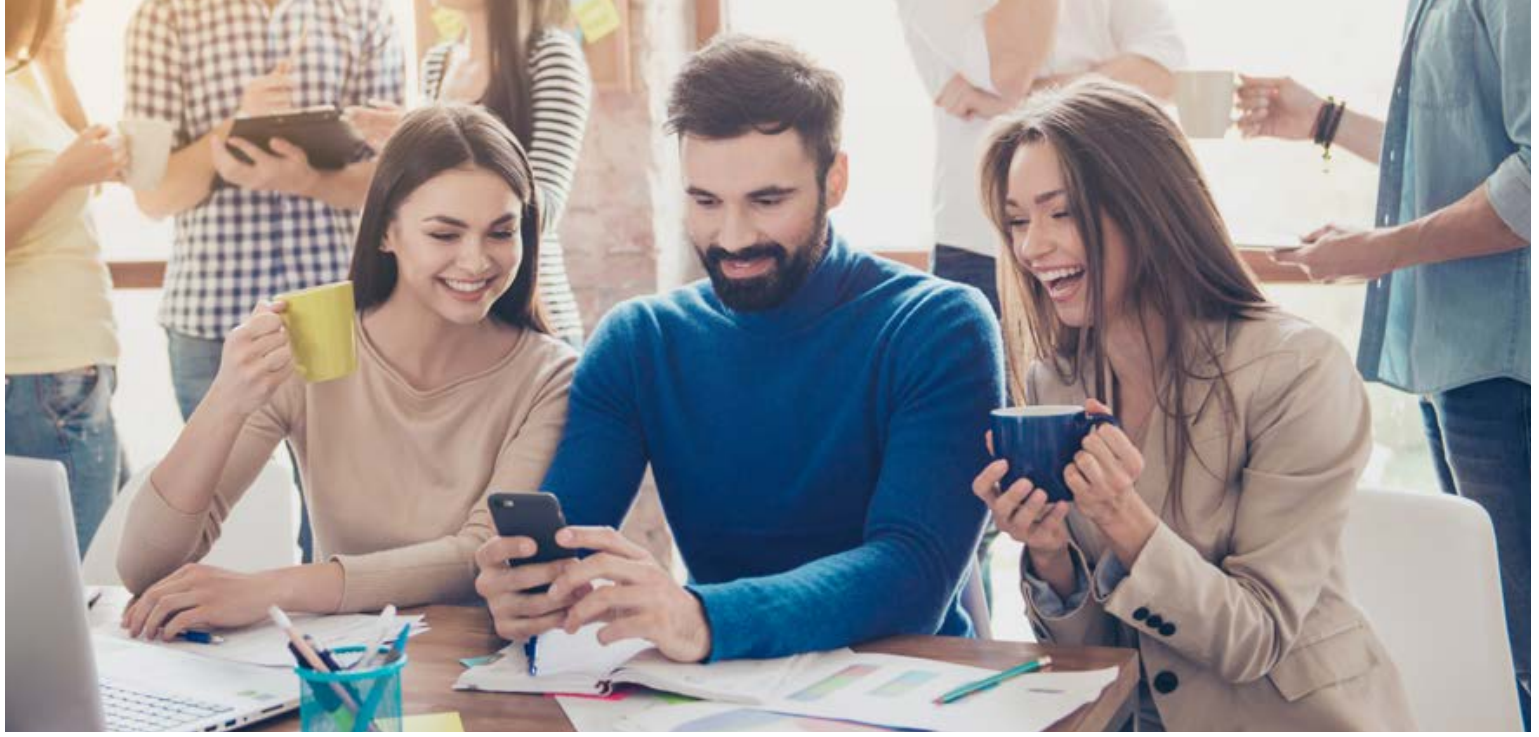

\title{
Programa Institucional de Calidad de Vida: Nuevas prácticas sociales para el desarrollo institucional y comunitario
}

DOI: http://dx.doi.org/10.18259/per.2019003

\author{
Dr. Carlos Enrique Tene Perez* \\ Universidad de Colima, México
}

\begin{abstract}
El Programa Institucional de Calidad de Vida de la Universidad de Colima puede considerarse un ejemplo de innovación social que contribuye a mejorar la calidad de vida de los universitarios y sociedad en general, mediante acciones que integran a las familias y disminuyen la vulnerabilidad de la sociedad ante factores de riesgo social.
\end{abstract}

a Universidad de Colima ha desarrollado un Programa Institucional de Calidad Le Vida, el cual constituye un modelo de implementación de nuevas prácticas sociales, que cuenta con la participación de estudiantes universitarios y catedráticos, en actividades universitarias orientadas al desarrollo de las colonias vulnerables, con lo cual ha contribuido al desarrollo de la propia institución educativa y de la comunidad.

Lógicamente, coadyuva la innovación social y no sería posible sin una estrategia de educación con responsabilidad social. Cada actividad de participación universitaria que se desarrolla en los planteles de la institución, con el fin de contribuir al desarrollo comunitario o social, se ejecuta, de manera coordinada, con el Centro de De- sarrollo de la Familia Universitaria (CEDEFU), dependencia universitaria de reciente creación (2014), dirigida por Alicia López de Hernández y orientada a sistematizar los esfuerzos orientados a mejorar la calidad de vida de los universitarios y la comunidad.

Anteriormente, los esfuerzos universitarios para el desarrollo institucional y comunitario se hacían de manera independiente a instancias de cada plantel Sin embargo, desde su aplicación, el programa en mención ha contribuido a establecer condiciones de mayor eficiencia y eficacia, que han favorecido nuevas prácticas sociales y han fortalecido las estrategias universitarias con responsabilidad social.

Las actividades que se realizan en el marco del Programa de Calidad de Vida de la Uni- 
versidad de Colima pueden ser clasificadas en varios rubros:

\section{- Acciones voluntarias y de capacitación}

Este modelo de gran impacto tiene como pilar importante las acciones voluntarias de estudiantes. Para dar una idea, durante el año pasado se realizaron 16 mil 300 acciones en las que participaron más de 4 mil 200 estudiantes voluntarios y se beneficiaron 166 mil 500 personas.

Cada estudiante realiza actividades para su formación integral y aplica así sus conocimientos en espacios reales como son las colonias, escuelas de educación primaria y de educación especial; diversas asociaciones civiles y entidades gubernamentales.

Otra cara de las acciones voluntarias es representada por la participación de las denominadas "Damas Voluntarias», que son esposas de directivos universitarios. Ellas, con su labor social, contribuyen también a las acciones de la Universidad de Colima.

\section{- El mirador de la cumbre}

La Universidad de Colima se vincula con el gobierno, la sociedad y entidades externas a través del programa institucional de calidad de vida, lo cual demuestra que la institución educativa es objeto de la confianza social y gubernamental. Un ejemplo de ello es la forma en que la institución educativa da vida a un centro comunitario denominado El Mirador de la Cumbre II, que está bajo la jurisdicción del Sistema Estatal para el Desarrollo Integral de la Familia, organismo público del gobierno del estado de Colima (México), el cual cedió ese espacio a la universidad en comodato. De esta forma, cada tarde se beneficia a los habitantes de la colonia, considerada vulnerable por el alto riesgo de problemas sociales.

Es común ver a padres y madres de familia, así como a jóvenes, niños y niñas, que acuden para recibir los beneficios derivados de los servicios que presta la universidad: clases de cocina, de nutrición saludable, guitarra, baile; orientación en temas legales; apoyo en tareas; actividades lúdicas y recreativas, entre muchas otras. El año pasado se beneficiaron más de 24 mil personas con estas actividades.

Hoy en día, el centro comunitario se ha convertido en un sitio al que acuden los pobladores de la colonia para acceder a eventos deportivos y culturales de alta calidad, actividades recreativas; charlas, talleres y brigadas que mejoran y continúan mejorando la calidad de vida de sus familias.

El centro comunitario, por tanto, constituye un espacio en el cual los estudiantes universitarios aplican lo aprendido en las

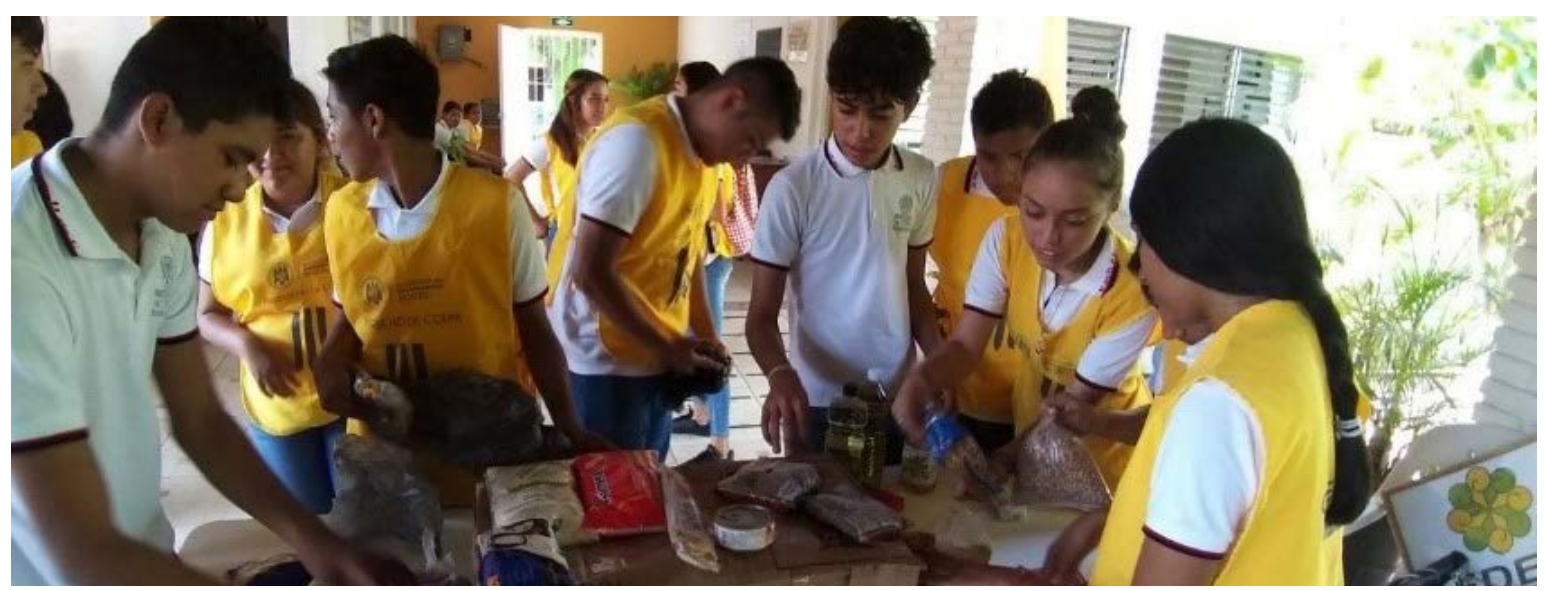

Trabajo voluntario con población vulnerable 
G. constituye un espacio en el cual los estudiantes universitarios aplican lo aprendido en las aulas, fortalecen su formación integral en valores, $y$, a la vez, aportan un beneficio a la sociedad.".

aulas, fortalecen su formación integral en valores, y, a la vez, aportan un beneficio a la sociedad.

\section{- Murmullos en los muros}

El Programa Institucional de Calidad de Vida no sólo coadyuva fortalecer una educación de calidad, sino que contribuye a construir una cultura de la paz y a combatir la inequidad. Por ejemplo, el Programa "Murmullos en los muros» incorpora a estudiantes, quienes crean murales para espacios universitarios y escuelas de educación básica.

Como podemos apreciar nuevamente, esta es una estrategia institucional exitosa que beneficia a los propios estudiantes para su formación integral y además a la sociedad, que accede a espacios de expresión artística. Además, coadyuva el desarrollo social en el marco de una cultura de la paz. En los dos últimos años ha permitido la creación de 23 murales que beneficiaron a más de 10 mil personas.

Existen otros programas dirigidos a alumnos de educación primaria, que aportan al fortalecimiento de la paz y la equidad social. Así, los programas Cultura Universitaria por la Paz Cocone Yocoya (del náhuatl cocone 'infante', y yocoya: 'crea') y UCol-Perai promueven la sana convivencia, sin violencia ni juicios negativos entre los niños y niñas de educación primaria, ya sea urbana o rural), y fortalecen los conocimientos en áreas como las matemáticas o el español; así como su desarrollo social, psicológico y educativo.
Nuevamente, aquí se vinculan jóvenes universitarios que se fortalecen, aplicando lo aprendido en las aulas y crean lazos de amistad perdurables, a la vez que amplían en niños y niñas la visión de ser futuros estudiantes universitarios.

\section{- Carrera rosa con causa}

Por tanto, en el programa institucional de calidad de vida se sientan las bases para una sociedad sana, segura y sin riesgos. Ejemplo de esto es que la universidad coadyuva la educación de la población en temas de salud, para así fortalecer su calidad de vida. Anualmente se organiza la denominada "Carrera Rosa con Causa" en la que participan la sociedad, junto con los universitarios.

Su propósito es sensibilizar a la sociedad para una detección oportuna de cáncer de mama, mediante la autoexploración. En otro rubro, los estudiantes participan en actividades que fortalecen la cultura de la protección civil y que les permiten responder de manera apropiada a eventuales contingencias.

Por otra parte, la Universidad cuenta con una Estancia Infantil para el desarrollo y cuidado de los hijos e hijas de trabajadoras universitarias, donde también se realizan simulacros y actividades de capacitación en temas de seguridad, que benefician directamente a los niños de los trabajadores.

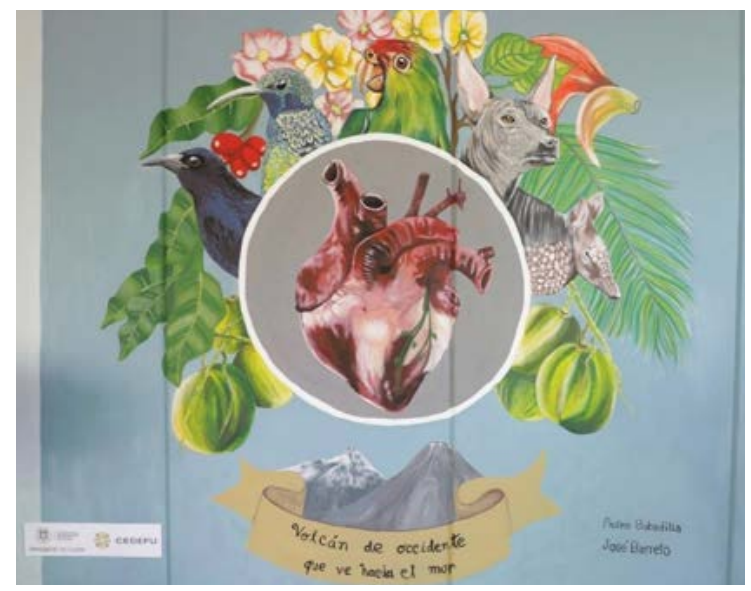

Mural "Corazón Colimote" 


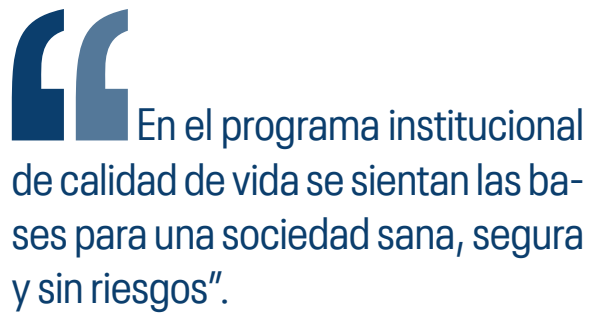

Asimismo, el compromiso de la universidad con la sociedad ha resultado evidente cuando los universitarios han donado toneladas de víveres e insumos de limpieza y aseo personal a familias que lo han requerido por ser damnificadas de fenómenos climatológicos.

Por otro lado, en el marco del Programa Institucional de Calidad de Vida también se coordinan servicios de prevención y detección oportuna de enfermedades en los llamados Módulos de Salud Universitaria, Módulos de Nutrición y en el Departamento Psicológico que han beneficiado en conjunto a más de 11 mil universitarios.

Cada año, se realizan las llamadas "Jornadas de prevención y detección de enfermedades a estudiantes» que benefician a 27 mil 749 alumnos. En ellas participan estudiantes de carreras del área de la salud.

Se cuenta con unidades móviles de salud que realizan acciones de detección y prevención de enfermedades en trabajadores de la institución con actividades como la medición de peso corporal, agudeza visual, presión arterial y detección de caries.

Asimismo, en la institución se atiende un programa gubernamental denominado espacios $100 \%$ libres de humo de tabaco, que fomenta la reducción del consumo de tabaco en instalaciones universitarias.

\section{Educación inclusiva sin fronteras}

A través del Programa Institucional de Calidad de Vida, la Universidad de Colima ha mostrado también su compromiso con las buenas prácticas inclusivas con una visión internacional. Ha participado en las acciones del Proyecto Internacional Muse, que fortalecen una educación inclusiva al lado de 11 instituciones de otros países. Con el Programa Voluntario Muse, los propios estudiantes apoyan a quienes tienen discapacidad, en actividades de gestión y con la realización de tareas que contribuyen a formar una sociedad incluyente.

Por todo lo anterior, el Programa Institucional de Calidad de Vida de la Universidad de Colima podría considerarse un modelo de implementación de prácticas educativas, de vinculación social para el fortalecimiento del desarrollo institucional propio y el comunitario. 